\title{
Augmenting Versatile Peroxidase Production from Lentinus squarrosulus and its Role in Enhancing Ruminant Feed
}

\author{
Aarthi Ravichandran, ${ }^{\mathrm{a}, \mathrm{b}}$ Ramya G. Rao, ${ }^{\mathrm{a}}$ Shanubhoganahalli Maheswarappa Gopinath, ${ }^{\mathrm{c}}$ \\ and Manpal Sridhar ${ }^{\mathrm{a}, *}$
}

Lentinus squarrosulus, a white-rot Basidiomycete, produces versatile peroxidase under nutrient-limiting conditions. This study was undertaken to enhance the yield of versatile peroxidase from the fungus by optimizing the physiological factors of nutrients and their concentration, inducers, temperature, and $\mathrm{pH}$. Optimal medium was devised using a central composite design - response surface methodology and experimental validation. The fungus produced high levels of versatile peroxidase at a C:N ratio of approximately 100 , temperature of $35^{\circ} \mathrm{C}$, and initial $\mathrm{pH}$ of 7 . Immobilization of Lentinus squarrosulus on inert polyurethane foam (PUF) with optimized medium for production enhanced the versatile peroxidase yield multifold. Maximal yield of versatile peroxidase achieved through optimization and immobilization strategies was $116 \mathrm{U} / \mathrm{mL}$. Efficacy of crude versatile peroxidase on aromatics degradation was illustrated through Fourier transform infrared analysis. The results demonstrated the improvised yield of versatile peroxidase from Lentinus squarrosulus and its efficiency in delignification of crop residues, substantiating the role of this enzyme in biotechnological applications especially for enriching ruminant feed.

Keywords: Versatile peroxidase; Optimization; Response surface methodology; Immobilization

Contact information: a: Bioenergetics and Environmental Sciences Division, ICAR-National Institute of Animal Nutrition and Physiology, Adugodi, Bengaluru 560 030, India; b: Women Scientist, Department of Science \&Technology (Govt. of India) New Delhi, India; c: Davanagere University, Davanagere, India;

*Corresponding author: manpalsridhar@yahoo.co.uk

\section{INTRODUCTION}

Lignocellulose, with its enriched network of biopolymers and abundance, plays important roles in diverse biotechnological applications. The recalcitrant nature of lignin concealing the energy-rich polysaccharides necessitates efficient deconstruction of this biomass for utilization in downstream applications (Ruiz-Dueñas and Martínez 2009). Nature, in due course of time, has evolved with diverse microorganisms to mineralize the complex macromolecule. Amongst them, white-rot fungi overshadow the biological lignin degraders through their integrated and exhaustive ligninolytic machinery (Dashtban et al. 2010; Wan and Li 2012).

Ligninases - including laccase, lignin peroxidase, manganese peroxidase, and versatile peroxidase - are crucial components of the ligninolytic machinery. The white-rot fungi engage collective action of these enzymes in mineralization of the complex macromolecule. Versatile peroxidase, an extracellular heme protein of the ligninolytic system, is endowed with polyvalent catalytic sites that render this protein with high redox potential (Camarero et al. 1999). Versatile peroxidase is regarded as a hybrid of lignin 
peroxidase and manganese peroxidase. This enzyme possesses the catalytic features of oxidation of aromatic compounds through long-range electron transfer (LRET) and Mn (II) to $\mathrm{Mn}$ (III), analogous to the latter peroxidase (Ravichandran and Sridhar 2017). Versatile peroxidase is a potential biocatalyst with relevance in a multitude of biotechnological applications.

The work on these lines has demonstrated that Lentinus squarrosulus is a saprophytic white-rot producing novel versatile peroxidase that is capable of selectively degrading lignin of the crop residues. Lignin peroxidase activity was not detected with this fungus. Versatile peroxidase has been produced by Lentinus squarrosulus during idiophase under conditions of nutrient depletion (Ravichandran et al. 2019). Nevertheless, proficient exploitation of the potential of this enzyme is reliant on its availability in large quantities. For this reason, enhancing the activity and yield of versatile peroxidase from this native isolate is of prime importance. Lignocellulose composition is perceived as a major determinant of the type and magnitude of the enzymes secreted (Sarnthima et al. 2009). Ex-situ production of these enzymes demands stringent environmental conditions simulating the natural niche of the fungi. This study was therefore intended to optimize the nutrient and the cultural parameters towards augmenting the versatile peroxidase activity of Lentinus squarrosulus.

In the fermentation process, multiple parameters interact and impact the output and its imperative for the optimization design to consider these effects. Such fermentation design will enable successful scale-up of the process for large-scale production of the enzyme. Response surface methodology with factorial design and regression analysis predicts the best response by simultaneous optimization of the variables with careful consideration of the interaction between the components (Bezerra et al. 2008). Apart from this, immobilization of fungal cells enables continuous operation of the fermentation process with single inoculation to maximize enzyme production by maintaining the biological activity (Nakamura et al. 1999). In this study, classical one-factor analysis was implemented and significant parameters affecting the enzyme activity in submerged fermentation were screened. The screened factors were fed as input to Response Surface Methodology (RSM), and the optimized response was predicted and validated. Consequently, fungal cells were immobilized on inert polyurethane foam (PUF) cubes with optimized medium for enzyme production. Efficacy of the enzyme produced was demonstrated by applying the versatile peroxidase-rich crude enzyme to crop residues and analysis of the degradation.

\section{EXPERIMENTAL}

\section{Reagents}

Veratryl alcohol, 2,6-dimethoxyphenol (DMP), and Reactive Black 5 (RB5) were purchased from Sigma Aldrich (St. Louis, MO, USA). All the reagents were of culture grade unless otherwise stated.

\section{Microbial Strain and Growth Conditions}

The fungus used in the study, Lentinus squarrosulus, is a tropical white-rot isolated from decaying wood and was deposited in Microbial Type Culture Collection (Accession No. 12292 ITS Genbank MH172168). Seed culture for fermentation was prepared in potato dextrose broth and basal fermentation medium composed of per liter: glucose $10 \mathrm{~g}$, 
ammonium dihydrogen orthophosphate $2 \mathrm{~g}$, yeast extract $2 \mathrm{~g}$, and microelement solution 1 $\mathrm{mL}$. Trace elements included $\mathrm{MgSO}_{4} 3 \mathrm{~g} / \mathrm{L}, \mathrm{CuSO}_{4} 0.005 \mathrm{~g} / \mathrm{L}, \mathrm{ZnSO}_{4} 0.1 \mathrm{~g} / \mathrm{L}, \mathrm{FeSO}_{4} 0.1$ $\mathrm{g} / \mathrm{L}$, and $\mathrm{CaCl}_{2} 0.05 \mathrm{~g} / \mathrm{L}$. Prior to inoculation, the cells were homogenized and added to the production medium.

\section{Screening of Media Components}

Independent factors of carbon sources, nitrogen sources, trace elements, inducers, and $\mathrm{pH}$ were varied one at a time to categorize the significant factors impacting versatile peroxidase production. Enzyme activity and biomass weight were recorded for ten days for each experiment. All experiments were performed in triplicates.

Carbon sources considered were glucose, cellobiose, lactose, maltose, fructose, sucrose, galactose, mannitol, glycerol, and xylan at $10 \mathrm{~g} / \mathrm{L}$ concentration. Ammonium dihydrogen orthophosphate, ammonium sulphate, ammonium oxalate, ammonium tartrate, mycological peptone, L-histidine, and L-arginine were studied as nitrogen sources at $2 \mathrm{~g} / \mathrm{L}$. Trace elements of $\mathrm{CuSO}_{4} 0.005 \mathrm{~g} / \mathrm{L}, \mathrm{FeSO}_{4} 0.1 \mathrm{~g} / \mathrm{L}, \mathrm{ZnSO}_{4} 0.1 \mathrm{~g} / \mathrm{L}, \mathrm{MgSO}_{4} 3 \mathrm{~g} / \mathrm{L}, \mathrm{CaCl}_{2}$ $0.05 \mathrm{~g} / \mathrm{L}$, and $\mathrm{CoCl}_{2} 0.005 \mathrm{~g} / \mathrm{L}$ were studied for their influence on mycelial growth and metabolism. Ligninolytic enzyme production is strongly stimulated by the presence of inducers especially organic acids that function in chelating $\mathrm{Mn}^{3+}$ ions, for effective degradation. To this effect, organic acids such as oxalic acid, glyoxylic acid, glycolic acid, malonic acid, tartaric acid, lactic acid, oleic acid, linoleic acid, and phenolic compounds such as guaiacol, ferulic acid, veratryl alcohol, 2,6 dimethoxyphenol, and polysorbate 80 (Tween 80) were added to the fermentation medium. Inducers were added at $5 \mathrm{mM}$ concentration, whereas polysorbate 80 was added at $10 \mu \mathrm{M}$ concentration. Parallel experiments with inducers addition concurrent with inoculation and addition of inducers on day 4 of inoculation after sufficient establishment of growth were conducted. The $\mathrm{pH}$ of the culture medium was varied from 3 to 7 to determine the effect of initial $\mathrm{pH}$ on enzyme activity.

Lignocellulose substrates are natural inducers of ligninolytic enzymes and accordingly diverse lignin-containing solid substrates, namely rice bran, wheat bran, rice husk, peanut shell, and saw dust, were used as solid substrates for growth and concomitantly versatile peroxidase production by Lentinus squarrosulus. The substrates were pretreated by consistent drying at $70{ }^{\circ} \mathrm{C}$ before inoculation. Sterilized solid substrate ( $2 \%$ to volume of the flask) was inoculated with homogenized fungus and incubated at appropriate conditions. Prior to assay, $10 \mathrm{~mL}$ of sterile water was added, agitated at 120 rpm for $1 \mathrm{~h}$, and used for enzyme studies. Concentration of optimal factors identified was then varied to determine the favorable range for versatile peroxidase production. Glucose concentration was varied from 0.7 to $20 \mathrm{~g} / \mathrm{L}$, whereas ammonium dihydrogen orthophosphate in the culture medium was studied at levels of 0.4 to $2 \mathrm{~g} / \mathrm{L}$.

\section{Optimization of Screened Components by RSM}

Factors from preliminary experiments, such as glucose, ammonium dihydrogen orthophosphate, peptone, yeast extract, oxalic acid, veratryl alcohol, 2,6 dimethoxyphenol, temperature, $\mathrm{pH}$, incubation time, and inoculum size, were chosen for optimization of versatile peroxidase activity from Lentinus squarrosulus. A two-factor interaction (2FI) model in central composite Design (CCD) under RSM was used to statistically optimize the versatile peroxidase activity from $L$. squarrosulus. Range of values chosen for each variable for the study design of 11 independent variables from L. squarrosulus are stated in Table 1. 
Table 1. Experimental Range for Individual Variables

\begin{tabular}{|c|c|c|c|c|}
\hline Factor & Name & Units & Min & Max \\
\hline$A$ & Incubation days & $\mathrm{d}$ & 3 & 10 \\
\hline$B$ & Temperature & ${ }^{\circ} \mathrm{C}$ & 30 & 50 \\
\hline$C$ & Initial $\mathrm{pH}$ & - & 3 & 7 \\
\hline$D$ & Inoculum size & $\%$ & 1 & 5 \\
\hline$E$ & Glucose & $\mathrm{g} / \mathrm{L}$ & 5 & 25 \\
\hline$F$ & Ammonium dihydrogen orthophosphate & $\mathrm{g} / \mathrm{L}$ & 0 & 5 \\
\hline$G$ & Yeast extract & $\mathrm{g} / \mathrm{L}$ & 0 & 1 \\
\hline$H$ & Peptone & $\mathrm{g} / \mathrm{L}$ & 0 & 4 \\
\hline$J$ & Veratryl alcohol & $\mathrm{g} / \mathrm{L}$ & 0 & 0.6 \\
\hline$K$ & 2,6 dimethoxy phenol & $\mathrm{g} / \mathrm{L}$ & 0 & 0.6 \\
\hline$L$ & Oxalic acid & $\mathrm{mM}$ & 0 & 15 \\
\hline
\end{tabular}

The two factor interaction model used in the study can be explained by Eq. 1,

$$
Y=\beta_{0}+\sum \beta_{i} X_{i}+\sum \beta_{i i} X_{i}^{2}+\sum \beta_{i j} X_{i} X_{j}
$$

where $Y$ represents the dependent response variable, $\beta_{0}$ is the regression coefficient, $\beta_{\mathrm{i}}$ is the linear effect, $\beta_{\mathrm{ii}}$ is the squared effect, and $\beta_{\mathrm{ij}}$ is the interaction effect of independent variable $X$. Design analysis and graphical representation (3D and contour plots) for the effect of independent variables on the response were performed with Design Expert (v.7.0.0, Stat-Ease, Minneapolis, MN, USA). Analysis of variance (ANOVA) was used to determine the significance of variables alone and between the variables (interaction). The predicted response through statistical optimization was experimentally validated for versatile peroxidase activity.

\section{Fungal Immobilization}

Pretreated and sterilized polyurethane foam cubes (PUF $1 \mathrm{~cm}^{3}$ ) at $2 \%$ to volume of the flask were inoculated with Lentinus squarrosulus in potato dextrose broth to promote growth. After sufficient establishment of growth on the PUF cubes, potato dextrose broth was decanted, and the cells were washed with saline. Subsequently, optimized production medium was added for versatile peroxidase production. Flasks with potato dextrose broth, instead of optimized production medium, served as the control. The activity profiles of cellulases, xylanases, proteases, laccase, versatile peroxidase, and total protein in optimized production medium and control medium were monitored for $18 \mathrm{~d}$.

\section{Analytical Measurements}

Laccase activity was determined through oxidation of 2,2'-azino-bis(3-ethyl benzothiazoline-6-sulfonic acid) (ABTS), and versatile peroxidase activity was assessed through RB5 and manganese oxidation (Kumar et al. 2015; Ravichandran et al. 2019). Laccase activity was followed through oxidation of $1.6 \mathrm{mM}$ ABTS in $100 \mathrm{mM}$ sodium acetate buffer $(\mathrm{pH} 4.5)$ at $420 \mathrm{~nm}\left(\varepsilon 420=36000 \mathrm{M}^{-1} \mathrm{~cm}^{-1}\right)$. The $0.5 \mu \mathrm{g} / \mathrm{mL}$ catalase was used to correct for ABTS oxidation by peroxidases. Manganese oxidation was detected using a reaction mixture with $0.5 \mathrm{mM} \mathrm{MnSO} 4$ and $100 \mathrm{mM}$ sodium malonate buffer (pH 4.5). Enzyme mediated formation of $\mathrm{Mn}^{3+}$ malonate complex was measured at $270 \mathrm{~nm}(\varepsilon 270=$ 
$11590 \mathrm{M}^{-1} \mathrm{~cm}^{-1}$ ). Oxidation of $10 \mu \mathrm{M}$ RB5 in $100 \mathrm{mM}$ sodium tartrate buffer (pH 3) was estimated at $598 \mathrm{~nm}\left(\varepsilon 598=24000 \mathrm{M}^{-1} \mathrm{~cm}^{-1}\right)$. Reactions with peroxidases were initiated with $0.1 \mathrm{mM} \mathrm{H}_{2} \mathrm{O}_{2}$. Cellulase activity was deduced with carboxymethyl cellulase as substrate. The assay mixture consisted of $0.25 \%$ substrate and $0.2 \mathrm{~mL}$ of sample in $50 \mathrm{mM}$ phosphate buffer with a $\mathrm{pH}$ of 6.8 (Agarwal et al. 1991). The procedure for xylanase estimation is like cellulase with the substrate being $0.06 \%$ oat spelt xylan.

Reducing sugars were estimated by the dinitrosalicylic acid (DNS) method (Miller 1959). Proteases were estimated by measuring the amount of proteins hydrolyzed during incubation with casein. Proteins were precipitated through $10 \%$ trichloroacetic acid (TCA) and estimated through Lowry's method (Lowry et al. 1951). Microbial biomass was deduced by filtering the media contents through pre-weighed dried Whatman no 1 filter paper followed by overnight drying at $70{ }^{\circ} \mathrm{C}$.

\section{Effect of Crude Versatile Peroxidase on Lignocellulose}

Enzyme harvested through immobilization was used to treat paddy straw and ragi straw at $45 \mathrm{U} / \mathrm{g}$ of straw. Paddy straw and ragi straw of approximately $1 \mathrm{~mm}$ particle size were treated with crude enzyme, the reaction was terminated, and samples were drawn at $4 \mathrm{~h}$ and $8 \mathrm{~h}$ by constant drying at $70^{\circ} \mathrm{C}$. Subsequently, the straws utilized for proximate analysis through neutral detergent fiber (NDF), acid detergent fiber (ADF), and acid detergent lignin (ADL) (Van Soest et al. 1991). To validate the effect of versatile peroxidase on improving the fiber digestibility for ruminant nutrition, in vitro dry matter digestibility (IVDMD) was assessed for the enzyme-treated and control straw samples without enzyme treatment (Minson and McLeod 1972).

\section{Fourier Transform Infrared (FTIR) Analysis}

To assess the decolorization of RB5 and kraft lignin by immobilized Lentinus squarrosulus, optimized production medium containing $0.01 \%$ RB5 and $0.02 \%$ kraft lignin were added to individual flasks and then incubated at $35^{\circ} \mathrm{C}$ at $80 \mathrm{rpm}$ and monitored for decolorization. Culture supernatant from immobilized fungal flasks and uninoculated control were analyzed through a Thermo Nicolet, Avatar 370 Fourier transform spectrometer (STIC, Cochin University of Science and Technology, Cochin, India) from $500 \mathrm{~cm}^{-1}$ to $4000 \mathrm{~cm}^{-1}$. Plots of the FTIR data, baseline correction and analysis were performed using Origin 2020 software (Origin lab, Northampton, USA).

\section{RESULTS AND DISCUSSION}

\section{Screening of Media Components}

Glucose was found to be the favorable carbon source for versatile peroxidase production by Lentinus squarrosulus followed by cellobiose. Poor response was observed with xylan. Biomass yield was similar with all the carbon sources except xylan. After 10 $\mathrm{d}$, glucose and cellobiose consumption was $100 \%$ and $99.69 \%$, respectively. The consumption range of lactose, maltose, fructose, and galactose was 85 to $89 \%$. Glucose concentration less than $10 \mathrm{~g} / \mathrm{L}$ was not suitable for versatile peroxidase production. However, concentration from $10 \mathrm{~g} / \mathrm{L}$ to $20 \mathrm{~g} / \mathrm{L}$ was suitable for enzyme production.

Ammonium dihydrogen orthophosphate, yeast extract, and peptone were the promising nitrogen sources; however, the use of peptone was discouraged due to its interference with enzyme activity. Ten Have et al. (1997) reported similar interference of 
peptone on lignin peroxidase activity where oxidation of veratryl alcohol was reported to be inhibited by peptone. The $\mathrm{C}_{2}$ organic acids, glycolic acid, glyoxylic acid, oxalic acid, phenolic compounds, guaiacol, 2,6 dimethoxy phenol, and veratryl alcohol were prominent to mention among the inducers studied. Oxalic acid, 2,6 dimethoxy phenol, and veratryl alcohol were potent inducers. Inducer addition after culture growth (4 days after inoculation) was more significant than addition of inducers concurrent with inoculation. Addition of manganese had an inhibitory effect on versatile peroxidase production (Cohen et al. 2002; Ravichandran et al. 2019), and hence manganese was avoided in the production medium. There was no significant difference in biomass with the parameters tested except for xylan, L-arginine, and L-histidine where biomass yield was comparatively lower.

Versatile peroxidase production with $\mathrm{Cu}^{2+}$ exhibited the most remarkable effect followed by $\mathrm{Zn}^{2+}$. There was no significant difference in biomass yield between control and the microelement supplemented cultures. Though copper is not directly involved in the activity of versatile peroxidase, copper is an activator for multiple catabolic enzymes such as lytic polysaccharide monooxygenases (LPMO) and glyoxal oxidases that are indirectly involved with versatile peroxidase activity (Eijsink et al. 2019). Glyoxal oxidases act in synergy with ligninolytic peroxidases and generate the peroxide necessary for activity of the latter enzymes. The $\mathrm{Fe}^{2+}, \mathrm{Zn}^{2+}$, and $\mathrm{Ca}^{2+}$ ions are involved in formation of the active conformation of the enzyme (Daou and Faulds 2017).

Fungal growth and associated versatile peroxidase activity were profound in the solid substrates studied, in general. This could be due to resemblance of solid substrate to the natural habitat of the fungi. Specifically, sawdust followed by rice bran was significant for versatile peroxidase production. However, accurate control and regulation of parameters in solid state fermentation was difficult due to the complex nature of the components. This poses a problem in scale-up of the fermentation process (Ergun and Urek 2017). Solid state fermentation of Lentinus squarrosulus on lignocellulosic substrates is illustrated in Fig. 1.

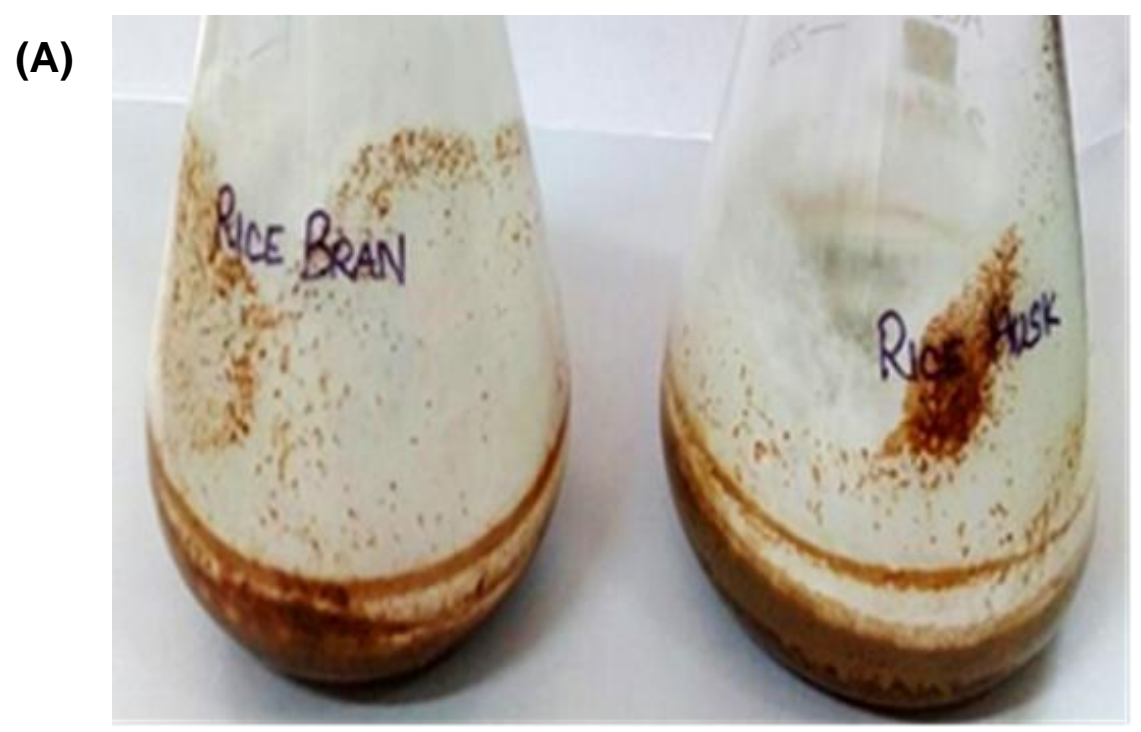

Fig. 1. (A) Lentinus squarrosulus on rice bran and rice husk substrates 


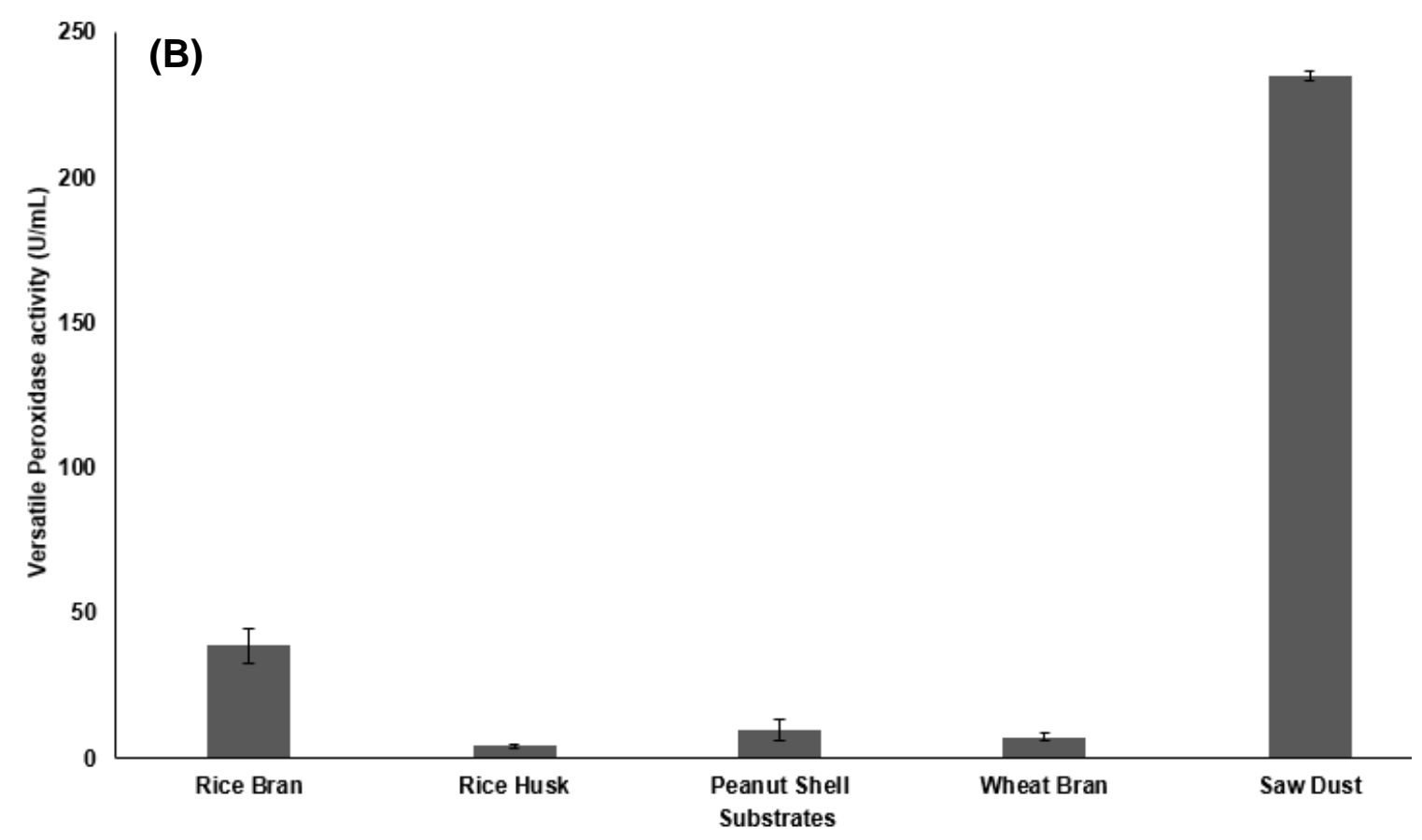

Fig. 1. (B) Versatile peroxidase activity on diverse solid substrates by Lentinus squarrosulus

It was observed that natural components related to lignocellulose specifically had a prominent influence in regulating versatile peroxidase production. This was evident through the significant carbon sources of glucose, cellobiose, the monosaccharide, and disaccharide form of cellulose. The inducers guaiacol and 2,6 dimethoxy phenol are natural components of lignin, whereas oxalic acid and veratryl alcohol are secreted by the whiterot fungi acting on lignocellulose (Hatakka 1994; Azadfar et al. 2015). This illustrated that rather than complete lignocellulose substrates, the components of the lignocellulose degradation cycle additionally play a role in regulating the expression of ligninolytic enzymes.

\section{Optimization through RSM}

Variables identified as optimum through One-Factor-At-a-Time (OFAT), viz. glucose, ammonium dihydrogen orthophosphate, yeast extract, peptone, veratryl alcohol, 2,6 dimethoxy phenol, and oxalic acid, were selected for evaluation through RSM. Statistical optimization of significant variables for maximizing versatile peroxidase production was performed with central composite design-response surface methodology (CCD-RSM), considering the above parameters along with temperature, $\mathrm{pH}$, incubation days, and inoculum volume. Next, 88 experimental trials were performed with 11 factors.

The ANOVA obtained from the regression analysis clearly illustrated the significance of individual and combined effect of these factors. Significance of factors was considered at a confidence interval of $95 \%$ with a p-value $<0.05 \%$. Analysis of variance showed that the factor $A$ (incubation period), and $G$ (yeast extract) were significant factors and $A C, A K, B C, B E, B K, C D, C G, C J, D G, D K, E J, F H, H L$, and $K L$ were significant model terms. The RSM model was highly significant with a model F-value of 3.33. The regression equation obtained from the study is shown in Eq. 2: 
Activity $=1.25303-0.764219 A-0.280699 B-0.1306 C-0.424144 D-0.29953 E-0.391369 F-$ $0.674435 G-0.308323 H-0.392387 J+0.275573 K-0.189471 L+0.563495 A B-1.01198 A C-$ $0.12009 A D+0.169874 A E+0.617199 A F+1.40851 A G+1.11321 A H+0.0577724 A J-$ $1.65884 A K+0.692676 A L-1.89487 B C-0.528407 B D-1.30574 B E+0.976931 B F+$ $0.357748 B G+0.358346 B H+0.208202 B J-1.68271 B K+0.691903 B L+1.11674 C D+$ $0.0162971 C E-0.495221 C F+1.34785 C G-0.0892495 C H+1.47961 C J+0.23014 C K-$ $0.153141 C L+0.709653 D E-0.7193 D F-1.4048 D G+0.150178 D H-0.415137 D J+$ $1.94664 D K-0.239767 D L-0.779324 E F-0.606699 E G-0.864257 E H+1.61941 E J-$ $0.35397 E K+0.00150829 E L-0.932595 F G-1.15012 F H-0.299215 F J-0.401812 F K+$ $0.000871941 F L-0.162896 G H-0.4111 G J+0.902609 G K-0.595274 G L-0.414758 H J+$ $0.106901 H K+1.34471 H L+1.46255 J K-0.793878 J L+1.39855 K L$

The optimal values of the variables were determined by maximization of the second-order polynomial equation with interaction terms obtained by multiple regression analysis based on CCD. Maximum activity obtained by the statistical optimization experiment was $24 \mathrm{U} / \mathrm{mL}$ with a minimal incubation period of $3 \mathrm{~d}$. The optimized conditions established are $\mathrm{pH}$ of 7 , glucose $25 \mathrm{~g} / \mathrm{L}$, yeast extract $0.25 \mathrm{~g} / \mathrm{L}, \mathrm{VA} 0.6 \mathrm{~g} / \mathrm{L}$, DMP $0.6 \mathrm{~g} / \mathrm{L}$ for an incubation time of $3 \mathrm{~d}$ with an inoculum size of $5 \%$ and constant rotation of $100 \mathrm{rpm}$ at $35^{\circ} \mathrm{C}$.

A remarkable observation to report is that the versatile peroxidase activity was linearly proportional to the $\mathrm{C}: \mathrm{N}$ ratio of the culture medium. The optimized medium had a $\mathrm{C}: \mathrm{N}$ ratio of 100:1, which is typical of that present in natural lignin substrates and was conducive for stimulating versatile peroxidase activity (Martin et al. 2014). This is evident from the 3D surface plot presented in Fig. $2 \mathrm{~A}$ and $2 \mathrm{C}$, which illustrates significant versatile peroxidase activity at high $\mathrm{C}: \mathrm{N}$ ratio whereas activity decreasing with a decrease in the $\mathrm{C}: \mathrm{N}$ ratio. In addition, laccase activity was trivial in media with high $\mathrm{C}: \mathrm{N}$ ratios. This could be attributed to the fact that laccases are induced in nitrogen-rich medium, with low $\mathrm{C}: \mathrm{N}$ ratios (Buswell et al. 1995; D’Agostini et al. 2011; Sakdaronnarong et al. 2012). Higher activity was consistently observed in culture medium with $\mathrm{C}: \mathrm{N}$ ratio irrespective of the presence of inducers. When 2,6 dimethoxyphenol and veratryl alcohol were added, the activity was further enhanced with the inducing effect of 2,6 dimethoxyphenol more pronounced than veratryl alcohol.
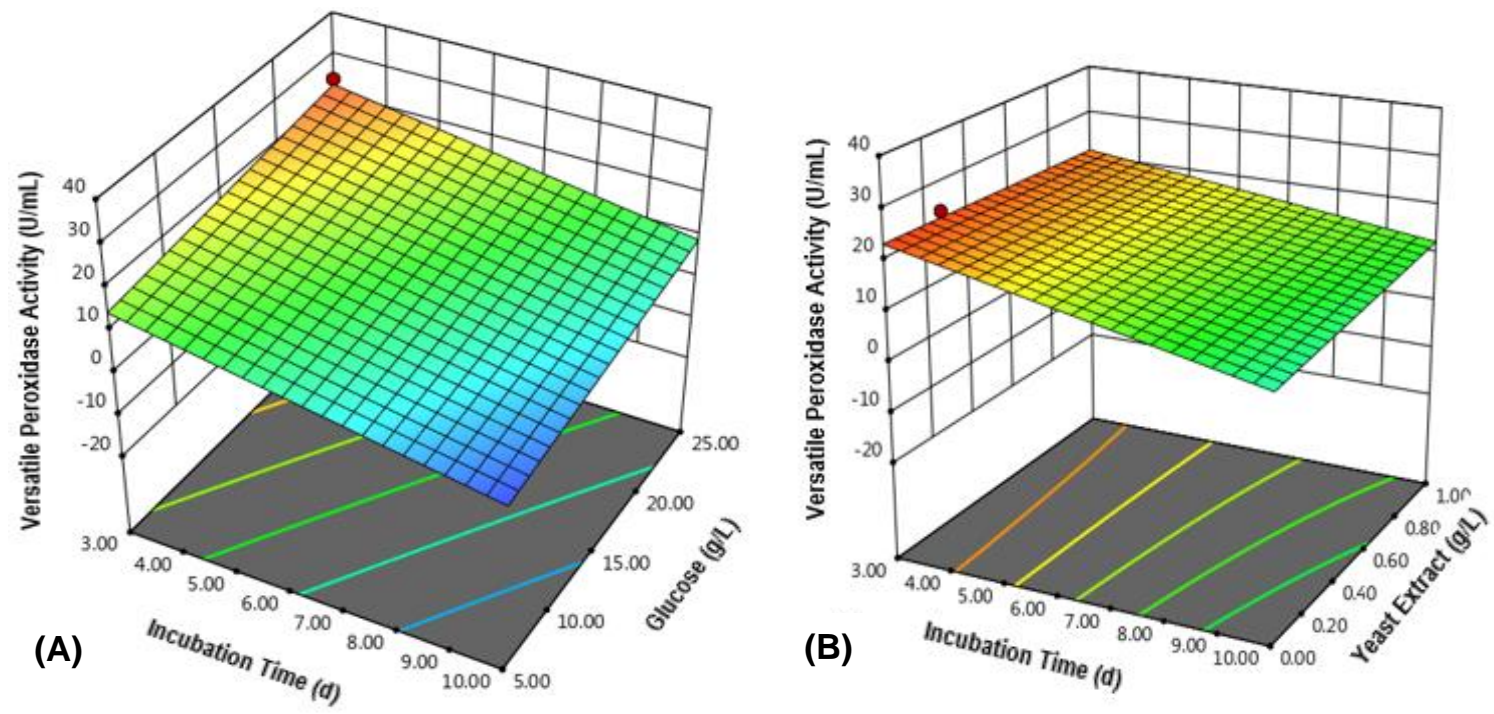

Ravichandran et al. (2021). "Peroxidase production," BioResources 16(1), 1600-1615. 

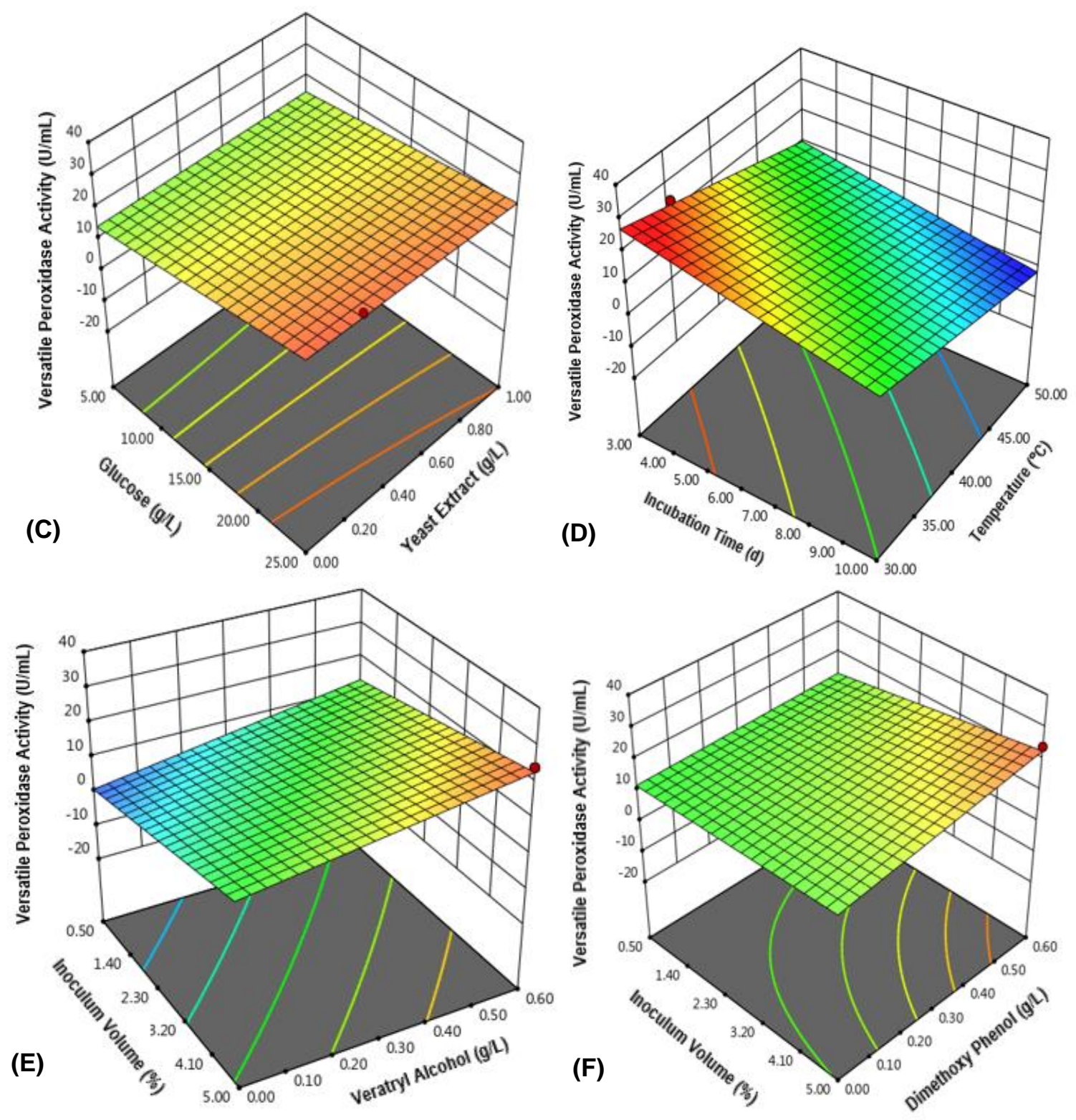

Fig. 2. 3D plot of interaction between experimental variables on versatile peroxidase activity illustrated through RSM: (A): incubation time (d) vs. glucose (g/L); (B): incubation time (d) vs. yeast extract $(\mathrm{g} / \mathrm{L}) ;(\mathrm{C})$ : glucose $(\mathrm{g} / \mathrm{L})$ vs. yeast extract $(\mathrm{g} / \mathrm{L})$; $(\mathrm{D})$ : incubation time $(\mathrm{d}) v s$. temperature $\left({ }^{\circ} \mathrm{C}\right) ;(\mathrm{E})$ : inoculum size $(\%)$ vs. veratryl alcohol $(\mathrm{g} / \mathrm{L})$; and $(\mathrm{F})$ : inoculum size $(\%) v s$. 2,6 dimethoxyphenol $(\mathrm{g} / \mathrm{L})$

The enzyme activity was comparable in the temperature range of 30 to $35^{\circ} \mathrm{C}$. Growth was perceived at temperatures up to $45^{\circ} \mathrm{C}$, whereas versatile peroxidase activity was not detectable at temperatures higher than $35^{\circ} \mathrm{C}$. At optimum temperature, significant activity was attained at shorter incubation times (2D). With the inoculum size of $5 \%$, optimum concentration of inducers was $0.6 \mathrm{~g} / \mathrm{L}$ (Fig. $2 \mathrm{E}$ and $2 \mathrm{~F}$ ). With all factors appropriate for production of versatile peroxidase, significant enzyme activity was detected in $3 \mathrm{~d}$ in the optimized culture medium. 


\section{Fungal Immobilization}

Immobilized Lentinus squarrosulus (Fig. 3) in optimized culture medium was superior to potato dextrose broth in production of biomass-degrading enzymes cellulase, xylanase, and versatile peroxidase.

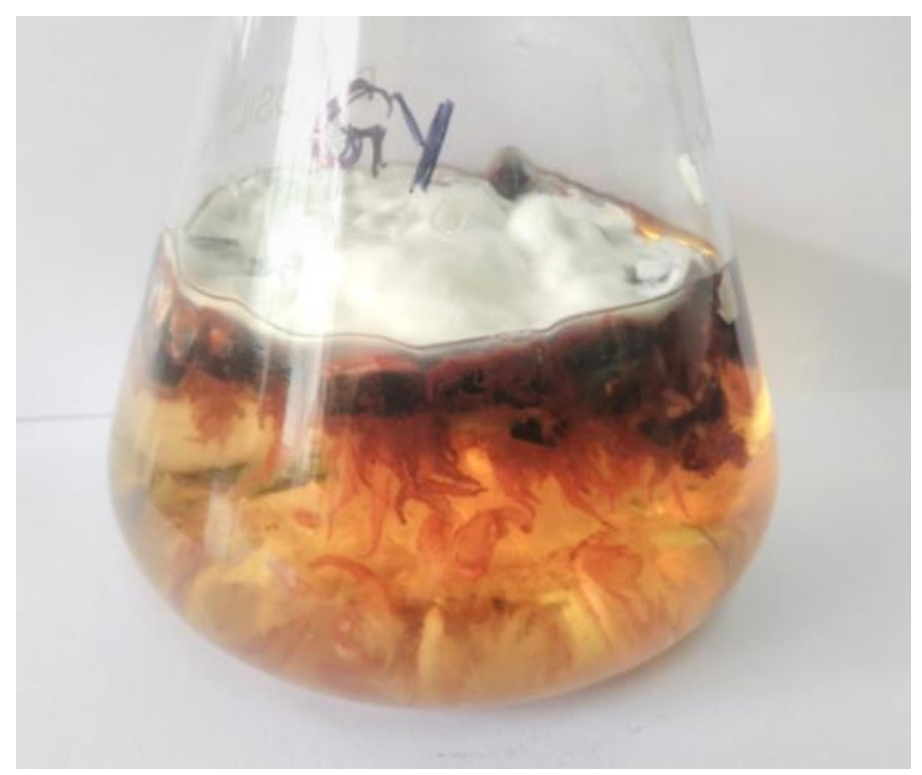

Fig. 3. Immobilized culture of Lentinus squarrosulus

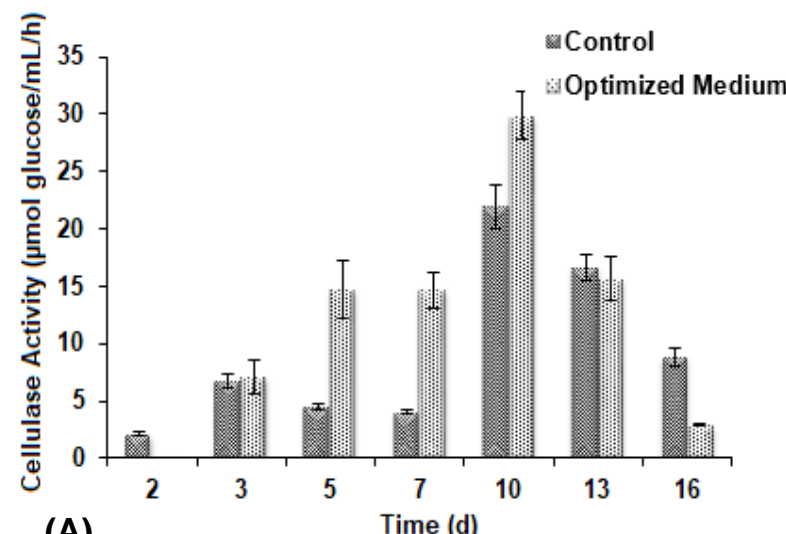

(A)
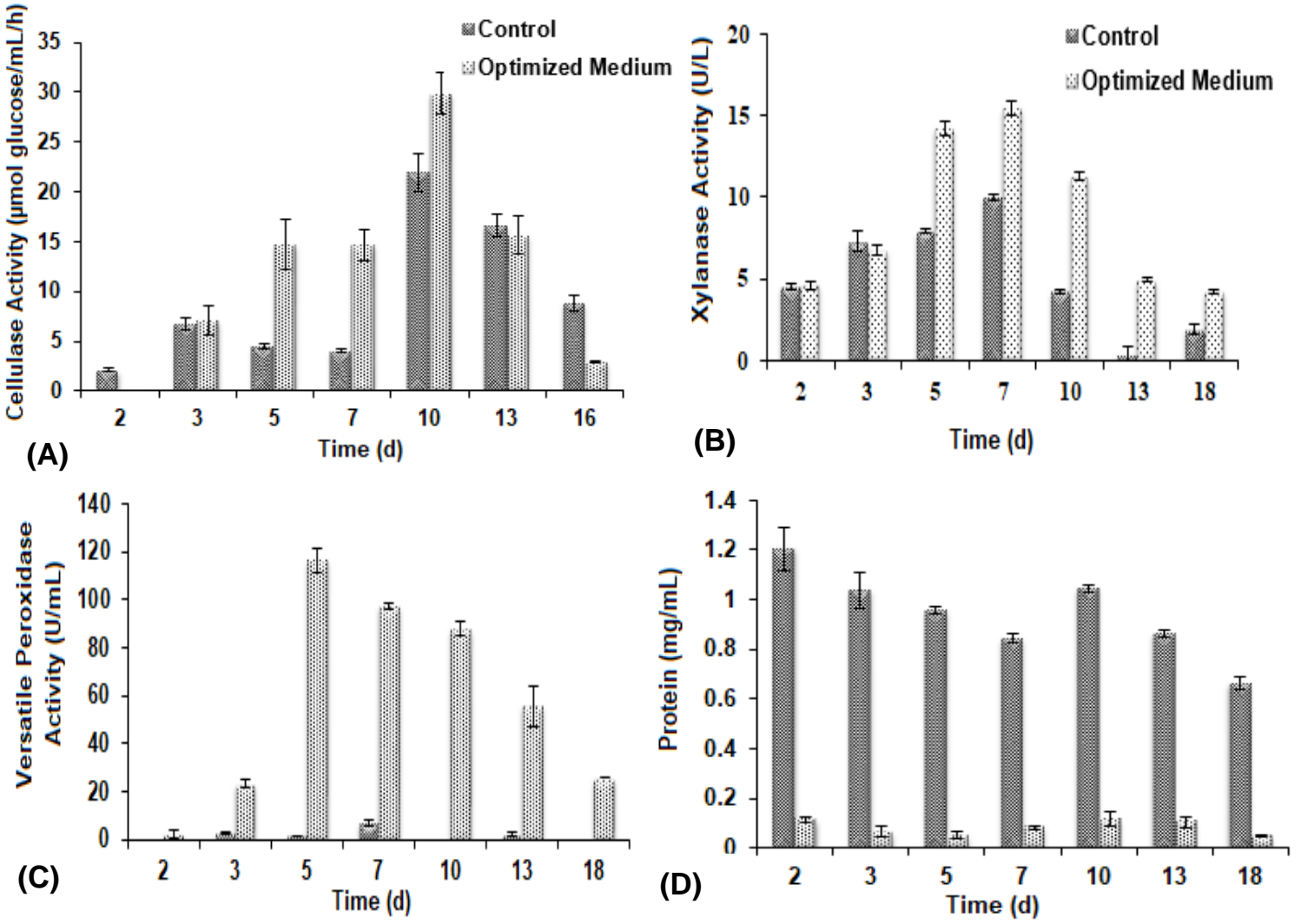

Fig. 4. Activity profile of biomass-degrading enzymes (A) Cellulase; (B) Xylanase; (C) Versatile Peroxidase; and (D) protein by immobilized Lentinus squarrosulus in control and optimized medium 
The activity profile of biomass-degrading enzymes in control and optimized medium is illustrated in Fig. 4.

Cellulase was higher on day-10 with cellulase activity of $30 \mu \mathrm{mol}$ glucose $/ \mathrm{mL} / \mathrm{h}$ and $25 \mu \mathrm{mol}$ glucose $/ \mathrm{mL} / \mathrm{h}$ in optimized and control medium, respectively. Xylanase activity in optimized and control production medium was $15.47 \mathrm{U} / \mathrm{L}$ and $9.92 \mathrm{U} / \mathrm{L}$ xylanase, respectively. Versatile peroxidase activity, as defined by manganese oxidation, was higher on day-5 with $116 \mathrm{U} / \mathrm{mL}$. Laccase activity in optimized medium was $2 \mathrm{U} / \mathrm{mL}$ and in control medium was $24 \mathrm{U} / \mathrm{mL}$. Protease activity was insignificant until $15 \mathrm{~d}$, and total protein was higher in potato dextrose control medium rather than the optimized production medium. Though versatile peroxidase activity was higher in the optimized medium, total protein was comparatively less than the control medium. This could be attributed to low nitrogen concentration in the optimized medium compared to the control. Specific activity of versatile peroxidase was thereby higher in the optimized medium.

Table 2. Proximate Composition and in vitro Digestibility of Crop Residues treated with Crude Versatile Peroxidase (VP)

\begin{tabular}{|c|c|c|c|c|c|}
\hline Straws & Sample & NDF (\%) & ADF (\%) & ADL (\%) & IVDMD (\%) \\
\hline \multirow{3}{*}{$\begin{array}{c}\text { Finger millet } \\
\text { straw }\end{array}$} & Control & $76.74 \pm 0.15$ & $46.66 \pm 0.48$ & $5.00 \pm 0.08$ & $40.12 \pm 0.86$ \\
\hline & $\begin{array}{c}\text { Crude } \\
\text { VP } \\
\text { treated } \\
4 \mathrm{~h}\end{array}$ & $66.92 \pm 0.42^{a \star \star}$ & $40.99 \pm 0.13^{a * *}$ & $4.71 \pm 0.04^{a *}$ & $46.95 \pm 0.48^{a \star *}$ \\
\hline & $\begin{array}{c}\text { Crude } \\
\text { VP } \\
\text { treated } \\
8 \mathrm{~h}\end{array}$ & $69.15 \pm 0.55^{a \star \star}$ & $41.39 \pm 0.24^{a * \star}$ & $4.60 \pm 0.06^{a^{*}}$ & $44.58 \pm 0.86^{b *}$ \\
\hline \multirow{3}{*}{ Paddy straw } & Control & $81.48 \pm 0.28$ & $62.05 \pm 0.23$ & $4.37 \pm 0.02$ & $41.34 \pm 0.98$ \\
\hline & $\begin{array}{c}\text { Crude } \\
\text { VP } \\
\text { treated } \\
4 \mathrm{~h}\end{array}$ & $73.78 \pm 0.44^{\mathrm{a} \star \star}$ & $58.76 \pm 0.14^{a * \star}$ & $4.29 \pm 0.02^{b}$ & $55.58 \pm 0.66^{a * *}$ \\
\hline & $\begin{array}{c}\text { Crude } \\
\text { VP } \\
\text { treated } \\
8 \mathrm{~h} \\
\end{array}$ & $78.15 \pm 0.27^{a \star \star}$ & $57.86 \pm 0.18^{a^{\star \star}}$ & $4.25 \pm 0.02^{b *}$ & $55.08 \pm 2.99^{a * *}$ \\
\hline
\end{tabular}

\section{Proximate Analysis}

Crude enzyme rich in versatile peroxidase from the immobilized culture of Lentinus squarrosulus was evaluated for delignification and enhancing digestibility of finger millet straw and paddy straw. Hydrogen peroxidase was added at the beginning of the reaction, and samples were withdrawn at frequent intervals to assess for proximate principles and digestibility. This was performed because stringent control of multiple process parameters 
is required for depolymerization and to control polymerization of the resultant aromatic species (Zeng et al. 2017). Depolymerization, as evident through proximate analysis, was better at $4 \mathrm{~h}$ than $8 \mathrm{~h}$. This could be because at increasing time intervals, products of depolymerization tend to polymerize again. Significant augmentation of digestibility $(\mathrm{P}<$ 0.05 ) was observed after $4 \mathrm{~h}$ of enzymatic reaction with an increase of $17 \%$ in finger millet straw and $34 \%$ in paddy straw compared to the control. Remarkable changes in composition and digestibility are presented in Table 2 . The results were indicative of the degradation ability of versatile peroxidase from Lentinus squarrosulus and a primary basis towards enhancing the digestibility of crop residues for better ruminant nutrition. Even a small increase in digestibility translates to significant improvement in ruminant productivity.

\section{FTIR Analysis}

Efficiency of oxidation by immobilized Lentinus squarrosulus was studied by supplementing the culture medium with kraft lignin and RB5. Culture supernatant was collected on day-7 after visible decolorization. Samples were analyzed through FTIR spectroscopy. The data was plotted and analyzed using Origin 2020 (Origin lab, Northampton, USA). The values of major peaks in control samples are indicated in Figs. 5A and 5B. Condensing of the peak around $1490 \mathrm{~cm}^{-1}$ in Fig. 5A provided evidence of cleavage of the azo bond in RB5. The peak at $1635 \mathrm{~cm}^{-1}$ indicated the associated formation of a primary amine group. Change in the small peak at $2071 \mathrm{~cm}^{-1}$ was the result of $\mathrm{CN}$ stretching vibration. The major peak at $3449 \mathrm{~cm}^{-1}$ in Fig. $5 \mathrm{~A}$ was the cumulative of the $\mathrm{OH}$ and $\mathrm{NH}$ stretching vibrations indicating the degradation of RB5 in the medium (Saroyan et al. 2019). Compared to RB5 oxidation analysis, oxidation of kraft lignin was less emphatic due to the complexity of the structure and duration of the reaction.

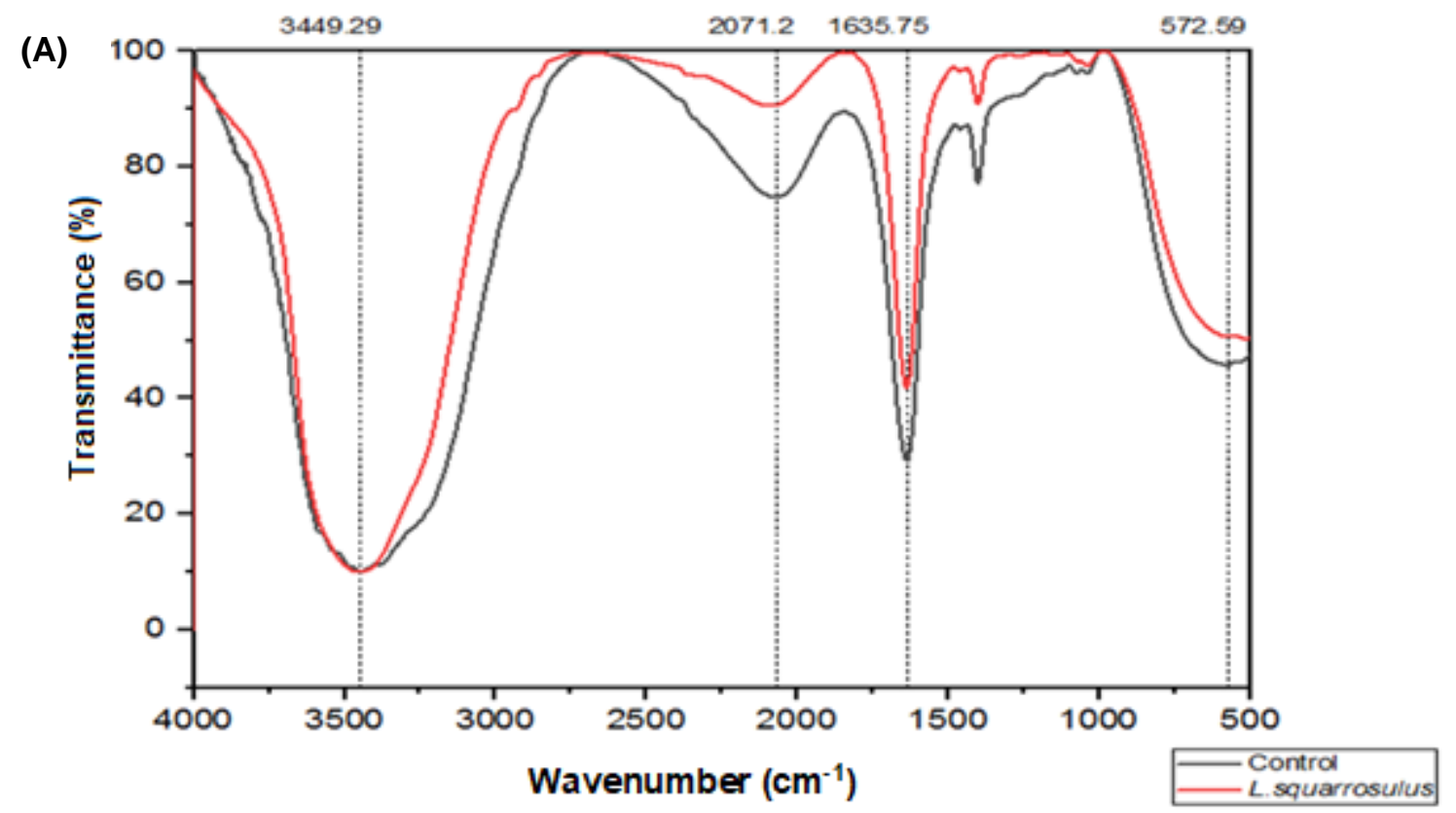




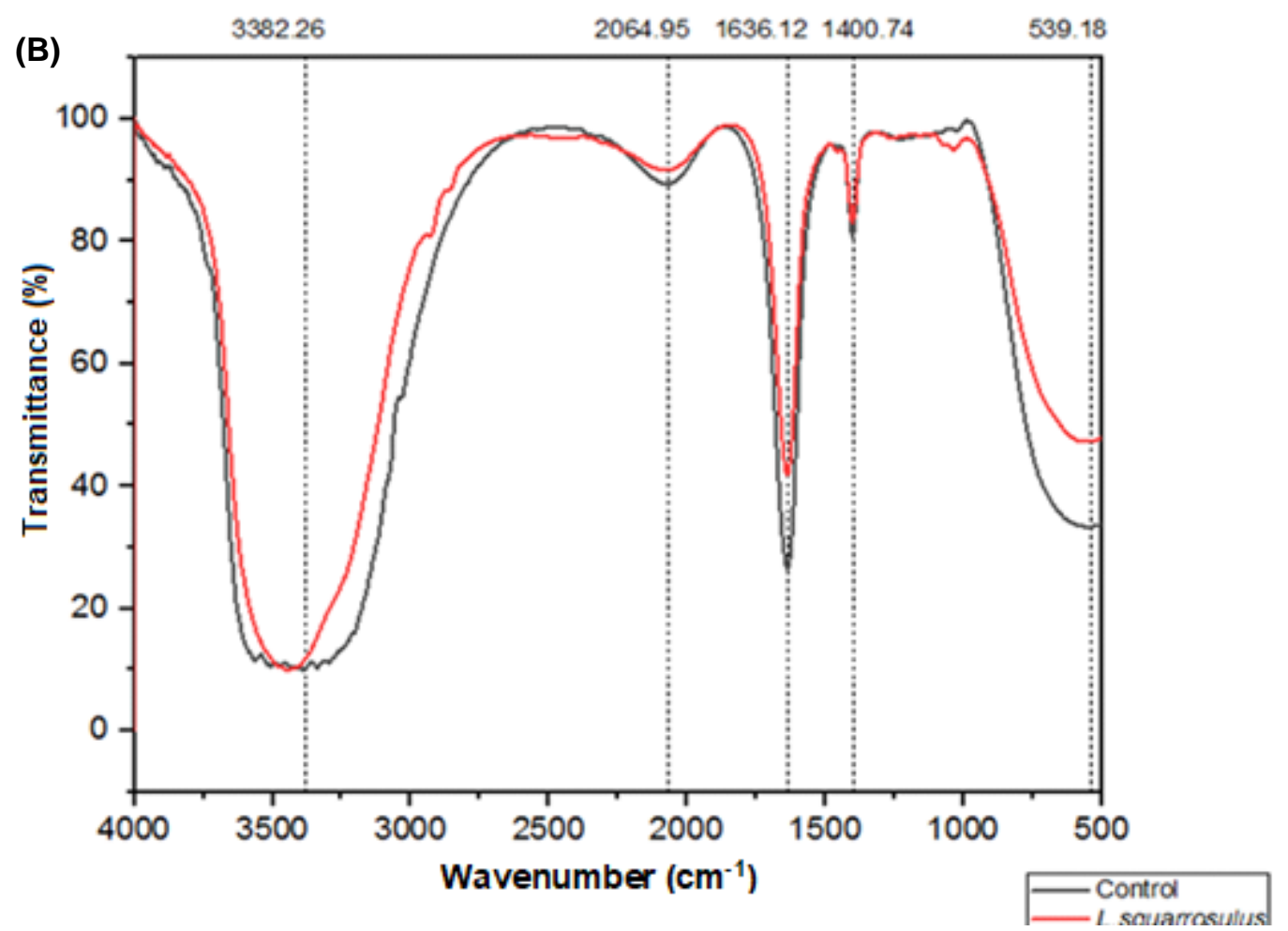

Fig. 5. (A) FTIR analysis of RB5 degradation by immobilized Lentinus squarrosulus; (B) FTIR analysis of kraft lignin degradation by immobilized Lentinus squarrosulus

The spectral changes indicated $\mathrm{O}-\mathrm{H}$ and $\mathrm{C}=\mathrm{C}$ stretching vibrations at $3382 \mathrm{~cm}^{-1}$ and $1636 \mathrm{~cm}^{-1}$, respectively. The $\mathrm{O}-\mathrm{H}$ plane vibrations were attributed by the phenolic and alcoholic hydroxyl groups. Stretching vibrations around $1636 \mathrm{~cm}^{-1}$ and $1400 \mathrm{~cm}^{-1}$ were characteristic of the cleavage of aromatic rings of the lignin molecule (Chen et al. 2016).

\section{CONCLUSIONS}

1. Optimization experiments elucidated that a high $\mathrm{C}: \mathrm{N}$ ratio, simulating the conditions of natural lignocellulose, yielded high versatile peroxidase activity. A nearly 10 -fold increase in enzyme activity was achieved through immobilization and optimization, with consistent activity across batches.

2. The efficacy of versatile peroxidase from immobilized Lentinus squarrosulus was established through enhanced digestibility of crop residues besides RB5 and kraft lignin degradation.

3. Cost effective production of versatile peroxidase and its potential in enhancing the digestibility of crop residues towards augmenting ruminant nutrition was demonstrated through this study. 


\section{ACKNOWLEDGEMENTS}

The financial assistance by Department of Science and Technology (DST), Ministry of Science and Technology, Govt. of India, under the WOS-A scheme (SR/WOSA/LS-32/2016) is gratefully acknowledged by the first author. The authors thank the Director, ICAR - National Institute of Animal Nutrition and Physiology, Bangalore (Karnataka) India, for providing the necessary facilities to carry out the research work.

\section{REFERENCES CITED}

Agarwal, N., Kewalramani, N., Kamra, D. N., Agarwal, D. K., and Nath, K. (1991). "Hydrolytic enzymes of buffalo rumen: Comparison of cell free rumen fluid, bacterial and protozoal fractions," Buffalo J. 7(2), 203-207.

Azadfar, M., Gao, A. H., Bule, M. V., and Chen, S. (2015). "Structural characterization of lignin: A potential source of antioxidants guaiacol and 4-vinylguaiacol," Int. J. Biol. Macromol. 75, 58-66. DOI: 10.1016/j.ijbiomac.2014.12.049

Bezerra, M. A., Santelli, R. E., Oliveira, E. P., Villar, L. S., and Escaleira, L. A. (2008). "Response surface methodology (RSM) as a tool for optimization in analytical chemistry," Talanta 76(5), 965-977. DOI: 10.1016/j.talanta.2008.05.019

Buswell, J. A., Cai, Y., and Chang, S. (1995). "Effect of nutrient nitrogen and manganese on manganese peroxidase and laccase production by Lentinula (Lentinus) edodes," FEMS Microbiol. Lett. 128(1), 81-87. DOI: 10.1019/0378-1097(95)00087-L

Camarero, S., Sarkar, S., Ruiz-Dueñas, F., Martinez, M. J., and Martinez, A. T. (1999). "Description of a versatile peroxidase involved in the natural degradation of lignin that has both manganese peroxidase and lignin peroxidase substrate interaction sites," J. Biol. Chem. 274, 10324-10330. DOI: 10.1074/jbc.274.15.10324.

Chen, J., Liu, C., Wu, S., Liang, J., and Lei, M. (2016). "Enhancing the quality of bio-oil from catalytic pyrolysis of kraft black liquor lignin," RSC Adv. 109, 10790-10797. DOI: 10.1039/C6RA18923G

Cohen, R., Yarden, O., and Hadar, Y. (2002). "Lignocellulose affects $\mathrm{Mn}^{2+}$ regulation of peroxidase transcript levels in solid-state cultures of Pleurotus ostreatus," Appl. Environ. Microbiol. 68(6), 3156-3158. DOI: 10.1128/AEM.68.6.3156-3158.2002

D’Agostini, É. C., Mantovani, T. R. D., DoValle, J. S., Paccola-Meirelles, L. D., Colauto, N. B., and Linde, G. A. (2011). "Low carbon/nitrogen ratio increases laccase production from basidiomycetes in solid substrate cultivation," Sci. Agric.

(Piracicaba, Braz.) 68(3), 295-300. DOI: 10.1590/S0103-90162011000300004

Daou, M., and Faulds, C. B. (2017). "Glyoxal oxidases: Their nature and properties," World J. Microbiol. Biotechnol. 33, Article number 87. DOI: 10.1007/s11274-0172254-1

Dashtban, M., Schraft, H., Syed, T. A., and Qin, W. (2010). "Fungal biodegradation and enzymatic modification of lignin," Int. J. Biochem. Mol. Biol. 1(1), 36-50. DOI: PMC3180040

Eijsink, V. G. H., Petrovic, D., Forsberg, Z., Mekasha, S., Røhr,Á. K., Várnai, A., Bissaro, B., and Vaaje-Kolstad, G. (2019). "On the functional characterization of lytic polysaccharide monooxygenases (LPMOs)," Biotechnol. Biofuels 12, Article number 58. DOI: 10.1186/s13068-019-1392-0 
Ergun, S. O., and Urek, R. O. (2017). "Production of ligninolytic enzymes by solid state fermentation using Pleurotus ostreatus," Ann. Agrar. Sci. 15(2), 273-277. DOI: 10.1016/j.aasci.2017.04.003

Hatakka, A. (1994). "Lignin-modifying enzymes from selected white-rot fungi: Production and role from in lignin degradation," FEMS Microbiol. Rev. 13(2-3), 125135. DOI: 10.1111/j.1574-6976.1994.tb00039.x

Kumar, V. P., Naik, C., and Sridhar, M. (2015). "Production, purification and characterization of novel laccase produced by Schizophyllum commune NI07 with potential for delignification of crop residues," Appl. Biochem. Microbiol. 51(4), 432441. DOI: $10.1134 / \mathrm{s} 0003683815040080$

Lowry, O. H., Rosebrough, N. J., Farr, A. L., and Randall, R. J. (1951). "Protein measurement with the Folin phenol reagent" Biol. Chem. 193(1), 265-275. DOI:PMID: 14907713

Martin, A. R., Erickson, D. L., Cress, W. J., and Thomas, S. C. (2014). "Wood nitrogen concentrations in tropical trees: Phylogenetic patterns and ecological correlates," New Phytol. 204(3), 484-495. DOI: 10.1111/nph.12943

Miller, G. L. (1959). "Use of dinitrosalicylic acid reagent for determination of reducing sugar," Anal. Chem. 31(3), 426-428. DOI: 10.1021/ac60147a030

Minson, D. J., and McLeod, M. N. (1972). "The in vitro technique: Its modification for estimating digestibility of large numbers of tropical pasture samples," CSIRO Div.Trop. Pastures Technical paper 8, 1-15. ISBN 0643000062

Nakamura, Y., Sungusia, M. G., Sawada, T., and Kuwahara, M. (1999). "Lignindegrading enzyme production by Bjerkandera adusta immobilized on polyurethane foam," J. Biosci. Bioeng. 88(1), 41-47. DOI: 10.1016/S1389-1723(99)80173-X

Ravichandran, A., and Sridhar, M. (2017). "Insights into the mechanism of lignocellulose degradation by versatile peroxidases," Curr. Sci. 113(1), 35-42. DOI: $10.18520 / \mathrm{cs} / \mathrm{v} 113 / \mathrm{i} 01 / 35-42$

Ravichandran, A., Rao, R. G., Thammaiah, V., Gopinath, S. M., and Sridhar, M. (2019). "A versatile peroxidase from Lentinus squarrosulus towards enhanced delignification and in vitro digestibility of crop residues," BioResources 14(3), 5132-5149. DOI: 10.15376/biores.14.3.5132-5149

Ruiz-Dueñas, F. J., and Martínez, A. T. (2009). "Microbial degradation of lignin: How a bulky recalcitrant polymer is efficiently recycled in nature and how we can take advantage of this," Microb. Biotechnol, 2(2), 164-177. DOI: 10.1111/j.17517915.2008.00078.x

Sakdaronnarong, C. K., Onsrithong, N., Suwankrua, R., and Jonglertjunya, W. (2012). "Improving enzymatic saccharification of sugarcane bagasse by biological/physicochemical pretreatment using Trametes versicolor and Bacillus sp," BioResources 7(3), 3935-3947.

Sarnthima, R., Khammuang, S., and Svasti, J. (2009). "Extracellular ligninolytic enzymes by Lentinus polychrous Lév. under solid-state fermentation of potential agroindustrial wastes and their effectiveness in decolorization of synthetic dyes," Biotechnol. Bioprocess Eng. 14, 513-522. DOI: 10.1007/s12257-008-0262-6

Saroyan, H. S., Ntagiou, D., Rekos, K., and Deliyanni, E. A. (2019). "Reactive Black 5 degradation on manganese oxides supported on sodium hydroxide modified graphene oxide," Appl. Sci. 9(10), Article ID2167. DOI: 10.3390/app9102167 
Ten Have, R., Hartmans, S., and Field, J. A. (1997). "Interference of peptone and tyrosine with the lignin peroxidase assay," Appl. Environ. Microbiol. 63(8), 33013303. DOI: .PMC168631

Van Soest, P. J., Robertson, J. B., and Lewis, B. A. (1991). "Methods for dietary fiber, neutral detergent fiber, and nonstarch polysaccharides in relation to animal nutrition," J. Dairy Sci. 74(10), 3583-3597. DOI: 10.3168/jds.S0022-0302(91)78551-2

Wan, C., and Li, Y. (2012). "Fungal pretreatment of lignocellulosic biomass," Biotech.Adv. 30(6), 1447-1457. DOI: 10.1019/j.biotechadv.2012.03.003

Zeng, J., Mills, M. J. L., Simmons, B. A., Kent, M. S., and Sale, K. L. (2017). "Understanding factors controlling depolymerization and polymerization in catalytic degradation of $\beta$-ether linked model lignin compounds by versatile peroxidase," Green Chem. 9, 2145-2154. DOI: 10.1039/C6GC03379B

Article submitted: September 7, 2020; Peer review completed: December 5, 2020;

Revised version received and accepted: January 10, 2021; Published: January 13, 2021.

DOI: 10.15376/biores.16.1.1600-1615 